\title{
Salivary gland involvement as initial presentation of Wegener's disease
}

\author{
Bert G. Vanhauwaert, Tania A. Roskams ${ }^{1}$, Stefan B. Vanneste and Daniel C. \\ Knockaert
}

Department of Internal Medicine and ${ }^{1}$ Histopathology, University Hospital Gasthuisberg, Herestraat 49, 3000 Leuven, Belgium

\begin{abstract}
Summary: We describe a case of Wegener's disease with massive painful bilateral submandibular gland enlargement as the presenting symptom. The diagnosis was based on histologically documented nasal mucosa involvement, focal necrotizing glomerulonephritis, episcleritis and anti-neutrophil cytoplasmic antibody.
\end{abstract}

\section{Introduction}

Wegener's granulomatosis is characterized by necrosis, granulomatous inflammation and vasculitis, and a classic triad of upper and lower respiratory tract involvement and glomerulonephritis. Other common clinical manifestations include fever, joint involvement, ocular abnormalities, skin lesions, central and peripheral nervous system involvement and pericarditis. ${ }^{1,2}$ Involvement of salivary glands in Wegener's disease is rare. ${ }^{1,3} \mathrm{We}$ present a case with bilateral submanibular gland involvement as a major initial manifestation.

\section{Case report}

A 60 year old woman was admitted to another hospital because of trismus and swelling of both submandibular glands. She had had fatigue for 6 weeks and 3 weeks before admission painful enlargement of the left submandibular gland was noticed, followed one week later by swelling of the right submandibular gland. Sialography was normal but computed tomography (CT) showed diffusely enlarged submandibular glands with areas of decreased density suggesting necrosis. Treatment with amoxycillin-clavulanic acid plus metronidazole brought no relief. Epistaxis and episcleritis developed and the trismus became even more pronounced. One week after admission the right submandibular gland was excised. Histopathological examination revealed diffuse paren-

Correspondence: D.C. Knockaert, M.D.

Accepted: 29 January 1993 chymal necrosis and inflammation with abscess formation and many multi-nucleated giant cells. Considerable capillary proliferation was noticed associated with fibrinoid necrosis (Figure 1). The picture was considered as pyogenic necrotizing sialadenitis associated with giant cell reaction to contrast material. She was subsequently referred to our centre, 4 weeks after the onset of enlargement of the submandibular glands.

At admission, she complained of general malaise, anorexia and dysphagia for swallowing. Physical examination disclosed a firm painful left submandibular gland, bilateral episcleritis and swollen eyelids.

The erythrocyte sedimentation rate was 140 $\mathrm{mm} /$ hour, the haemoglobin value was $112 \mathrm{~g} / \mathrm{dl}$, the leucocyte count $14.1 \times 10^{9} / 1 \quad(81 \%$ polymorphonuclears), the platelet count was $404 \times 10^{9} / 1$. Serum creatinine was normal as well as aminotransferase values, creatine kinase and lactic dehydrogenase. Alkaline phosphatase and gammaglutamyltranspeptidase was elevated, $326 \mathrm{IU} / 1$ (normal to 130) and $92 \mathrm{IU} / 1$ (normal to 28), respectively. Urinalysis revealed erythrocyturia with morphologically abnormal erythrocytes but no proteinuria. Angiotensin converting enzyme value was normal, anti-nuclear antibody and antineutrophil cytoplasmic antibody (ANCA) tests were negative.

Chest X-ray was normal but sinus films showed signs of bilateral maxillar and ethmoidal sinusitis. There were no signs of bony destruction on computed tomography of the sinuses.

Examination showed an inflamed nose mucosa, and nasal mucosa biopsy revealed an intense 

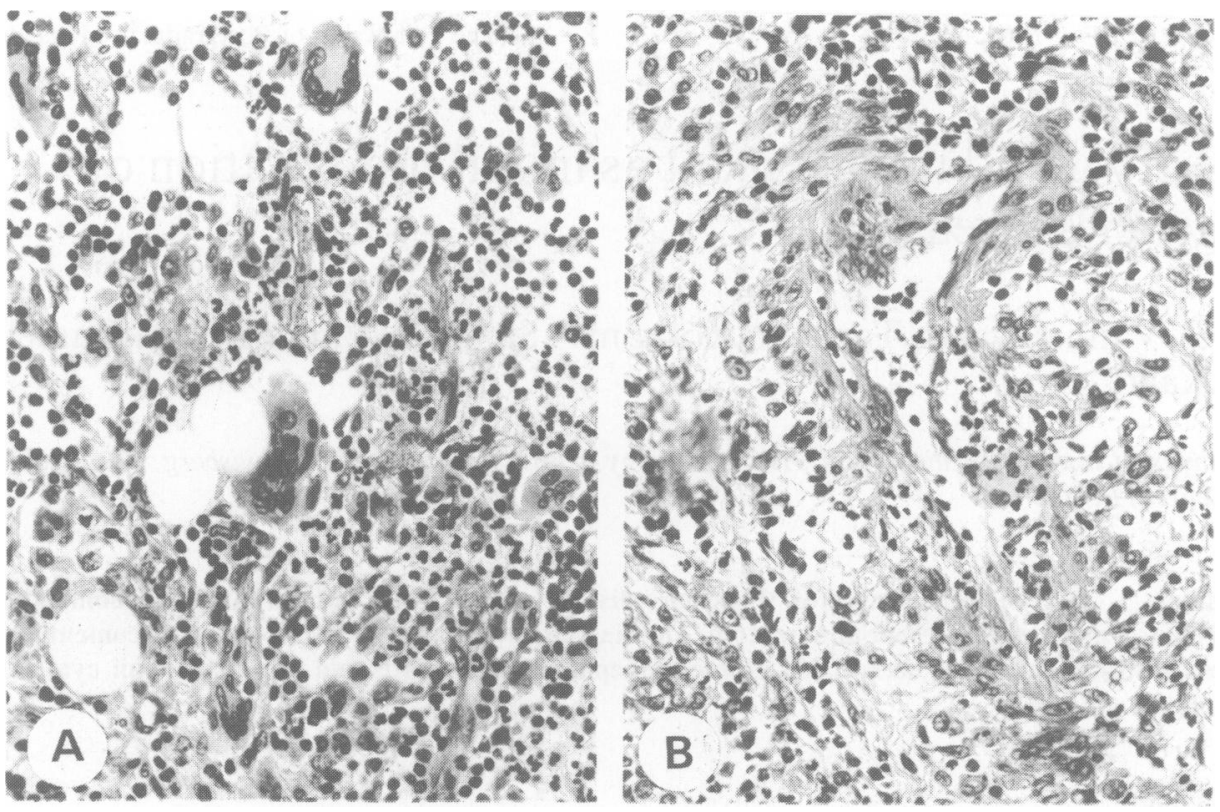

Figure 1 Submandibulary gland biopsy. (A) Inflammatory infiltrate with many multi-nucleated giant cells. (B) Vessel $\vec{\nabla}$ wall, infiltrated by polymorphonuclear leucocytes and surrounded by epitheloid histiocytes, polymorphonuclear leucocytes and lymphocytes. (Haematoxylin \& eosin $\times 250$ ).

inflammation with microabscesses surrounded by lymphoplasmocytes and epitheloid-like cells but no vasculitis. Wegener's disease was suggested but the negative anti-neutrophil cytoplasmic antibody test and the extensive necrotizing purulent inflammation of the salivary glands were considered as arguments against the diagnosis. Renal biopsy showed focal necrotizing glomerulonephritis and a second ANCA test performed 14 days after referral to our institution was positive (c-ANCA, titre 1/64).

The diagnosis of Wegener's disease was made and treatment with corticosteroids and cyclophosphamide resulted in gradual regression of the signs of inflammation and the enlargement of the left submandibular gland.

\section{Discussion}

Wegener's disease is a systemic inflammatory disease and hence can affect almost any organ system. Ear, nose and throat symptoms are very common but salivary gland involvement is rarely reported. ${ }^{4}$ We could trace 16 cases of salivary gland involvement in Wegener's granulomatosis reported since 1960 and seven of which had involvement of the submandibular gland. ${ }^{3,5-12}$

The rarity of salivary gland involvement in Wegener's granulomatosis is further demonstrated by the prospective clinical and therapeutic studye Fauci, describing 85 patients with Wegene? granulomatosis followed over a 21 year period at the National Institutes of Health in the USA. Only을 one of these patients showed involvement of the parotid gland.' In the recent update of their experience these authors describe biopsy-provenoํㅡㄹ involvement of the parotid gland in less than $1 \%$ of 158 patients. $^{2}$ A histopathological study from the same institute reporting on 126 head and neck biopsy specimens of 70 patients with Wegener's disease describes acute or chronic vascular:changes, necrosis, microabscesses and poorly? formed granulomas in salivary gland biopsies of three of the 70 patients. ${ }^{5}$ Salivary gland abnor-을 malities were not discussed in a study emphasizing the ear, nose and throat symptoms in 22 patients. ${ }^{4}$ 글

Salivary gland involvement seems to be an early feature of Wegener's disease which probably explains the sparing of the kidneys found in $\mathrm{a}_{\odot}^{N}$ number of these cases. ${ }^{3}$ Our case study also under- $N$ lines the value of repeated anti-neutrophil cytoplasmic antibody testing with suspicion of Wegener's $\omega$ disease. ${ }^{13}$

Inflammatory conditions of the salivary glands? encompass infections - viral, such as mumps, bacterial and chronic granulomatous diseases such ${ }^{+}$ as tuberculosis, actinomycosis, syphilis and others - in addition to noninfective inflammatory diseases. In this latter group Sjögren's syndrome $\frac{?}{\mathbb{Q}}$ 
and sarcoidosis are by far the most common. ${ }^{14}$ Recent reports and our case emphasize the importance of Wegener's disease as a cause of salivary gland involvement particularly in a context of multi-system disease. The histopathologic findings are diffuse necrotizing inflammation with abscess formation in addition to granulomatous features such as giant cells and aggregates of lymphocytes and epitheloid cells. Vasculitis may also be seen. The vasculitis is described as necrotizing or granulomatous without many further details. ${ }^{3,7}$ Although these findings are not specific for Wegener's disease, knowledge of this picture should suggest the diagnosis in case of suspected multi-system disease and particularly when accompanied by involvement of the upper or lower respiratory tracts and the kidneys as in our case. ${ }^{17}$

\section{References}

1. Fauci, A.S., Haynes, B.F., Katz, P. \& Wolff, S.M. Wegener's granulomatosis: prospective clinical and therapeutic experience with 85 patients for 21 years. Ann Intern Med 1983 98: 76-85.

2. Hoffman, G.S., Kerr, G.S., Leavitt, R.Y. et al. Wegener granulomatosis: an analysis of 158 patients. Ann Intern Med 1992, 116: 488-498.

3. Specks, U., Colby, T.V., Olsen, D.K. \& Deremee, R.A Salivary gland involvement in Wegener's granulomatosis. Arch Otolaryngol Head Neck Surg 1991, 117: 218-223.

4. D'Cruz, D.P., Asherson, R.A. \& Hughes, G.R.V. Ear, nose, and throat symptoms in subacute Wegener's granulomatosis. Br Med J 1989, 299: 419-422.

5. Devaney, K.O., Travis, W.D., Hoffman, G., Leavitt, R., Lebovics, R. \& Fauci, A.S. Interpretation of head and neck biopsies in Wegener's granulomatosis. Am J Surg Pathol 1990, 14: 555-564.

6. Bachmayer, K., Ludwig, H. \& Radaszkiewicz, T. Eine 60 jährige Patientin mit Sialadenitis, Lungenrundherden und Ulcus vulvae. Wien Klin Wochenschr 1984, 96: 289-294.

7. Murty, G.E., Mains, B.T. \& Bennett, M.K. Salivary gland involvement in Wegener's granulomatosis. $J$ Laryngol Otol 1990, 104: 259-261.

8. Kovarsky, J. Parotid nodules in Wegener's granulomatosis. Arthritis Rheum 1978, 21: 864-865.

9. Kavanaugh, A.F. \& Huston, D.P. Wegener's granulomatosis presenting with unilateral parotid enlargement. Am J Med 1988, 85: $741-742$.
The differential diagnosis of granulomatous sialadenitis is shown in Table I.

Table I Causes of granulomatous sialadenitis

Granulomatous reaction to extravasation of mucus due to obstruction by calculi or tumour ${ }^{15}$

\section{Sarcoidosis}

Infections (mycobacterial, toxoplasmosis tularemia, cat scratch disease, actinomycosis, fungi, syphilis)

Inflammatory diseases (Wegener's disease, Crohn's disease)

Foreign body granulomas due to sialographic contrast medium $^{15,16}$

10. Berman, D.A., Rydell, R.E. \& Eichenholz, A. Wegener's granulomatosis: a clinico-pathologic study of four cases. Ann Intern Med 1963, 59: 521-530.

11. Small, P., Black, M., Davidman, M., Brisson de Champlain, M.L., Kapusta, M.A. \& Kreisman, H. Wegener's granulomatosis and relapsing polychondritis: a case report. $J$ Rheumatol 1980, 7: 915-918.

12. Smith, G.A. \& Konrad, H.R. Pathologic quiz case 3. Arch Otolaryngol 1976, 102: 320-321.

13. Nolle, B., Specks, U., Lüdemann, J. et al. Anticytoplasmic auto-antibodies: their immunodiagnostic value in Wegener granulomatosis. Ann Intern Med 1989, 11: 28-40.

14. Johnson, A. Inflammatory conditions of the major salivary glands. Ear Nose Throat J 1989, 68: 94-98.

15. Van der Walt, J.D. \& Leake, J. Granulomatous sialadenitis of the major salivary glands. A clinicopathological study of 57 cases. Histopathology 1987, 11: 131-144.

16. Batsaki, J.G. Granulomatous sialadenitis. Ann Otol Rhinol Laryngol 1991, 100: 166-169.

17. Leavitt, R., Fauci, A.F., Bloch, D.A. et al. The American College of Rheumatology 1990 criteria for the classification of Wegener's granulomatosis. Arthritis Rheum 1990, 33: 1101-1107. 